\title{
Particle size effect on water vapor sorption measurement of organic shale: One example from Dongyuemiao Member of Lower Jurassic Ziliujing Formation in Jiannan Area of China
}

\author{
Rui Yang ${ }^{1 \oplus} *$, Aoqi $\mathrm{Jia}^{1}$, Qinhong $\mathrm{Hu}^{2}$, Xiaowen Guo ${ }^{1}$, Mengdi Sun ${ }^{1}$ \\ ${ }^{1}$ Key Laboratory of Tectonics and Petroleum Resources, Ministry of Education, China University of Geosciences, Wuhan 430074, P. R. \\ China \\ ${ }^{2}$ Department of Earth and Environmental Sciences, The University of Texas at Arlington, Arlington, TX 76019, USA
}

Keywords:

Organic shale

particle size effect

water vapor sorption

areal hysteresis index

GAB model

dent model

Cited as:

Yang, R., Jia, A., Hu, Q., Guo, X., Sun, M. Particle size effect on water vapor sorption measurement of organic shale: One example from Dongyuemiao Member of Lower Jurassic Ziliujing Formation in Jiannan Area of China. Advances in Geo-Energy Research, 2020, 4(2): 207-218, doi: 10.26804/ager.2020.02.09.

\begin{abstract}
:
Shale formations generally contain a certain amount of water, and the occurrence of water can strongly affect the free gas content and gas storage capacity within shale. Although some studies have conducted water vapor adsorption tests to understand the water adsorption behavior and water-shale interactions, surprisingly the influence of grain size on water vapor sorption of shale is poorly understood. In this work, water vapor adsorption experiments on one Dongyuemiao shale from Ziliujing Formation in Jiannan Area, with different particle sizes (8-12 mesh, 20-35 mesh, 35-80 mesh, 80-200 mesh, and $>200$ mesh) are conducted over a wide relative humidity $(\mathrm{RH})$ range (5\%-95\%) using a gravimetric method. The influence of particle size on water vapor adsorption measurement is investigated and the optimal particle size is suggested for water vapor experiment. Results show that the maximum uptake of water vapor adsorption is smaller in larger particle sized sample, which is related to the variation of accessible pores. Monolayer adsorption capacity obtained from Guggenheim-Anderson-de Boer modelling tends to increase as the particle size increases, suggesting a stronger water vapor adsorption potential. Comparative studies show that 20-35 mesh is suggested to be the optimum particle size for comparative purpose. The quantity of adsorption on the primary and secondary sites is comparable or equals at a $\mathrm{RH}$ range of approximately $60 \%-80 \%$. When $\mathrm{RH}$ value is smaller than $60 \%$, the quantity of water vapor adsorption on the primary site dominates, while adsorption uptake on the secondary site plays a dominant role when $\mathrm{RH}$ value is greater than $80 \%$. When particle size increases, water vapor adsorptions on the primary sites increases slightly, while a decrease trend is observed for water vapor adsorption on secondary sites.
\end{abstract}

\section{Introduction}

Over the past two decades, hydrocarbon (including natural gas and petroleum) production from low-permeable shale formations has increased rapidly in North America, leading to a worldwide 'shale revolution' (EIA, 2018). One of the key technologies for the success of 'shale revolution' is multistage hydraulic stimulation, which requires a great amount of water (Hughes, 2013; Ghanbari and Dehghanpour, 2016). During the hydraulic simulation process, enormous amounts of fracturing fluids mixed with groundwater (several million gallons) have been injected into the target shale reservoirs to create multiple microfractures and increase connectivity of pore-fracture network (Singh, 2016; Wang et al., 2017). During the post-stimulation flow period, injected fluids should flow back from the stimulated well before shutting-in the well. However, in practice, a small fraction (only $6-10 \%$ on average) of the initial injected water is recovered, as indicated by decades-long experience from some typical shale gas plays in North America (e.g., 5\% of the total injection volume in Haynesville Shale) (King, 2012; Vandecasteele et al., 2015; Singh, 2016). Therefore, a large amount of water has been retained in the subsurface and flowed into shale reservoir, which is characterized by poor physical property (Loucks et

${ }^{*}$ Corresponding author.

E-mail address: yangyingrui@cug.edu.cn (R. Yang); dimpluto@cug.edu.cn (A. Jia); water19049@gmail.com (Q. Hu);

guoxw@cug.edu.cn (X. Guo); sunmd@cug.edu.cn (M. Sun). 2207-9963 (C) The Author(s) 2020.

Received May 15, 2020; revised May 27, 2020; accepted May 27, 2020; available online June 1, 2020. 
al., 2009; Cai and Yu, 2010; Cai et al., 2017; Han et al., 2020; Liu et al., 2020). The retained liquid water often occurs as adsorbed or free states in the shale pore spaces, which could strongly affect free gas content, storage capacity, gas diffusivity and permeability in shale (Ross and Bustin, 2009; Ji et al., 2012; Gasparik et al., 2014; Li et al., 2019a; Cai et al., 2020). Besides, some clay minerals in shale can expand/swelling and even form micro-fractures while adsorbing water molecules (Chenevert, 1970; Makhanov et al., 2014; Lyu et al., 2015; Ghanbari and Dehghanpour, 2016; Zolfaghari et al., 2017a). Some researchers reported that a strong correlation existed between the volume of injected water and shale gas production (Nicot and Scanlon, 2012; Ghanbari and Dehghanpour, 2016). Therefore, the characterization of water vapor adsorption/desorption of shale samples is a crucial issue, which is beneficial to estimate of shale gas in place, to improve shale gas flowback rate and to understand the fate of hydraulic fracturing fluids.

Water vapor adsorption describes the relationship between water activity and the equilibrium moisture content for a solid material at constant pressure and temperature. For years, measurements of water vapor adsorption have been focused on pure adsorbents, such as active carbon (Barton et al., 1991; Do and Do, 2000), alumina (Kim et al., 2003; Serbezov, 2003), silica (Inagaki et al., 1996), food material (Adam et al., 2000) and coal (Charrière and Behra, 2010; Švábová et al., 2011). Previous studies have found that water vapor adsorption behaviors can be influenced by many factors, e.g., pore shape and size concerning capillary condensation, pore-volume, interaction with pore surface concerning the wettability, water contact angle and surface roughness (Inagaki et al., 1996; Yamashita et al., 2013; Kimura and Yamauchi, 2016; Yang et al., 2018b). Compared to previous studies on pure adsorbents, highly heterogeneous shale rock has distinct laminated layers, and it is composed of different contents of organic matter and inorganic minerals (e.g., different types of clay minerals). In particular, reactive clay minerals (e.g., smectite) have a higher number of active interlayers and can provide more area for monolayer water coverage than less reactive clays (e.g., illite) (Hatch et al., 2012; Feng et al., 2018; Sang et al., 2019).

Recently, water vapor adsorption has gradually caught the attention in the oil/gas industry and academia, some researchers conducted theoretical and experimental studies about water vapor adsorption/desorption on different shales or clay minerals (Zolfaghari et al., 2017a; Feng et al., 2018; Shen et al., 2018; Li et al., 2019a; Sang et al., 2019). Previous studies about water vapor adsorption mainly focus on the relatinship between water content and methane adsorption capacity (Joubert et al., 1974; Gasparik et al., 2014; Li and Krooss, 2017; Zou et al., 2018; Yang et al., 2020), effect of water vapor adsorption on pore structure parameters (Zolfaghari et al., 2017b; Feng et al., 2018), micro-distribution characteristics of adsorbed and free water ( $\mathrm{Li}$ et al., 2019a), kinetic of water adsorption (Tang et al., 2017; Duan and Li, 2018), effect of clay minerals on water sorption behavior (Zolfaghari et al., 2017a), and moisture adsorption modelling (Feng et al., 2018; Shen et al., 2018, 2019; Sang et al., 2019). Although water vapor adsorption measurements have been conducted on different shale rocks to understand water adsorption behavior and water-shale interactions, surprisingly the influence of grain size of shale used in different studies is poorly understood. Due to the different sample sizes used in previous measurements, it is difficult to compare those reported data directly. Analytical size fractions, such as powder for pure clay minerals (Feng et al., 2018), 0.1-0.15 $\mathrm{mm}$ for pure clay and shale from the Ordos Basin (Li et al., 2016), 0.125-0.15 mm for Marcellus Shale (Tang et al., 2017), 0.18-0.25 mm for shale samples from the Illinois Basin (Sang et al., 2019), 0.25-0.38 mm for shales from Upper Ordovician Wufeng and Lower Silurian Longmaxi Formations in Changning Area (Duan and $\mathrm{Li}, 2018$ ), and 0.5$0.8 \mathrm{~mm}$ for shales from Lower Silurian Longmaxi Formation (Shen et al., 2018), were used in the literature, which makes their results difficult to compare. Some researchers have conducted gas (e.g., carbon dioxide and nitrogen) adsorption on organic-rich shale and coal samples with various sample sizes to discuss the influence of particle size on pore structure characteristics (Chen et al., 2015; Han et al., 2016; Mastalerz et al., 2017). Their studies revealed that gas physisorption results were significantly affected by grain size and they observed a noticeable increase in mesopore volume, specific surface area and porosity when the sample size was smaller than a critical value. A reduction in grain size has changed the pore structure of shale by increasing the accessibility of pore spaces (Tinni et al., 2014). Compared to carbon dioxide and nitrogen adsorptions, water vapor adsorption could be more complicated because the strong hydrogen bonds of water molecules and water-rock interactions could exist simultaneously (Tang et al., 2017; Sang et al., 2019). Considering that pore structure of carbonaceous porous materials can be significantly influenced by particle size, which in turn affects water vapor adsorption behavior; thus, it is very crucial to explore the influence of particle size toward water vapor adsorption behavior of organic shale.

In this work, water vapor sorption is conducted on one organic shale sample from Dongyuemiao Member of Lower Jurassic Ziliujing Formation in Jiannan Area, which is a promising shale gas reservoir in South China. Using an accurate gravimetric method, water vapor adsorption measurements are conducted on the shale sample with different particle sizes (i.e., 8-12 mesh, 20-35 mesh, 35-80 mesh, 80-200 mesh, and $>200$ mesh). Considering that powder shale samples (greater than 200 mesh) are required for mineral composition and geochemical analysis, such as total organic carbon (TOC) and minerals composition tests, thus, the properties for shale samples with different particle sizes used in this work, e.g., mineral composition and TOC content, can be assumed to be approximately the same. Therefore, the influence of particle size on water vapor measurement can be explored and the optimal particle size for water vapor adsorption isotherm is suggested. In addition, the effects of particle size on the hysteresis loop, and primary and secondary adsorption capacity are investigated using the Guggenheim-Anderson-de Boer (GAB) and Dent models to fit the experimental isotherm data.

\section{Experiments}

In this work, one downhole black shale sample from 
Table 1. Basic information of the core sample used in this work (Yang et al., 2018a).

\begin{tabular}{|c|c|c|c|c|c|c|c|c|c|}
\hline \multirow{2}{*}{ Well } & \multirow{2}{*}{$\begin{array}{l}\text { Depth } \\
\text { (m) }\end{array}$} & \multirow{2}{*}{$\begin{array}{l}\text { TOC content } \\
\text { (wt. } \%)\end{array}$} & \multirow{2}{*}{$\begin{array}{l}\text { Thermal } \\
\text { maturity (\%) }\end{array}$} & \multirow{2}{*}{$\begin{array}{l}\text { Kerogen } \\
\text { type }\end{array}$} & \multirow{2}{*}{$\begin{array}{l}\text { Porosity from mercury } \\
\text { intrusion }(\%)\end{array}$} & \multicolumn{4}{|c|}{ Main mineral composition (wt.\%) } \\
\hline & & & & & & quartz & k-feldspar & carbonate & clays \\
\hline Jianye \#1 & 623 & 2.1 & $1.1-1.3$ & $\mathrm{II}_{1}$ & 1.95 & 37.0 & 4.0 & 2.0 & 55.0 \\
\hline
\end{tabular}

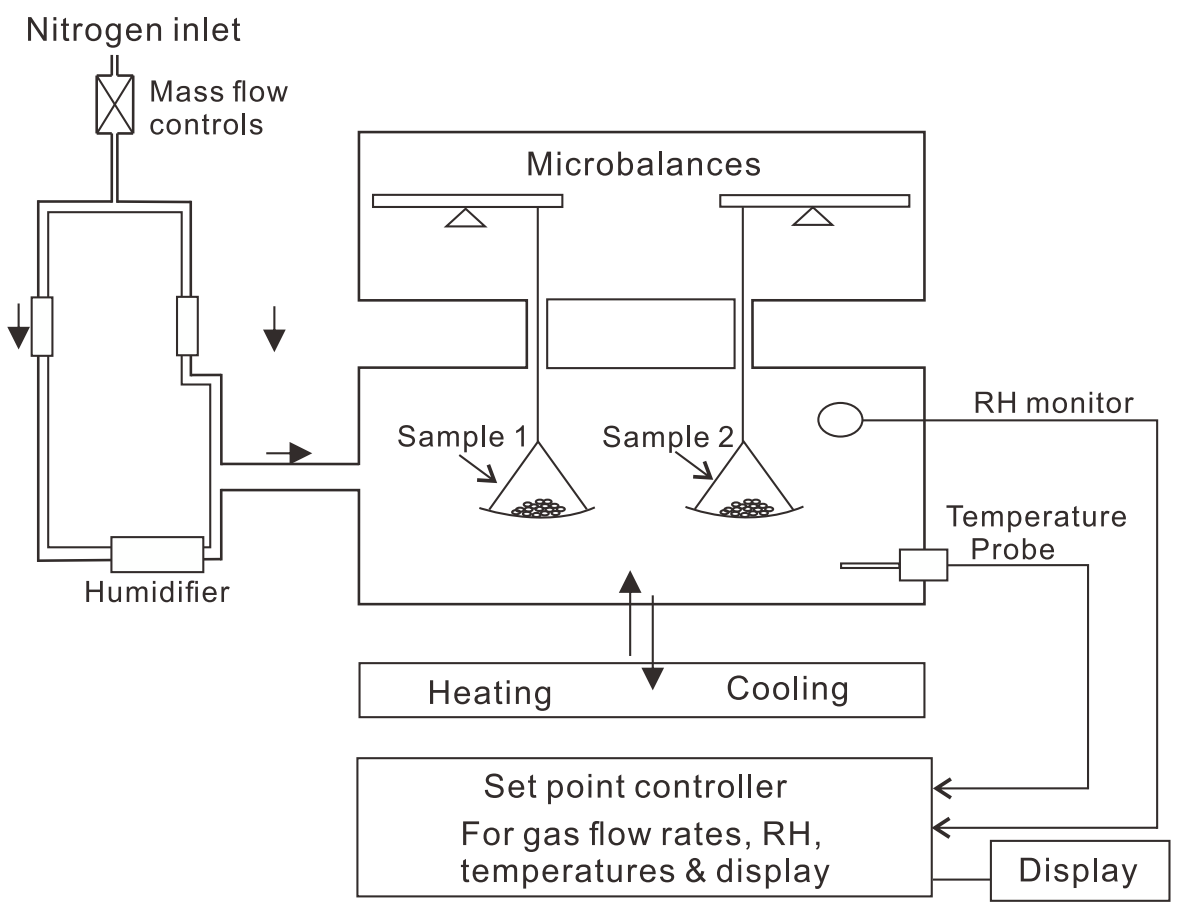

Fig. 1. Schematic diagram of the Aquadyne DVS-2 water sorption analyzer for measuring adsorption equilibrium isotherms.

Dongyuemiao Member in Lower Jurassic Ziliujing Formation was collected from well Jianye \#1 in Jiannan Area, western Hubei Province. Our previous studies showed that the TOC content of this shale sample was $2.1 \mathrm{wt} . \%$, indicating an organic-rich shale. Mineral composition was dominated by clay (55.0 wt.\%) and quartz (37.0 wt.\%), with few $k$-feldspar and carbonate (Table 1). Kerogen maceral analysis had shown that the kerogen type in Dongyuemiao Member from Lower Jurassic Ziliujing Formation was dominated by type $\mathrm{II}_{1}$. The thermal maturity of Dongyuemiao Member varies in a range of 1.1-1.3\% $R_{o}$, suggesting in the peak of oil generation stage. The detail properties of the core sample are listed in Table 1.

Prior to water vapor adsorption analysis, shale sample is milled and screened to obtain a series of different particle sizes (8-12 mesh, 20-35 mesh, 35-80 mesh, 80-200 mesh, and $>200$ mesh, which corresponds to $1.70-2.36 \mathrm{~mm}, 0.5-$ $0.85 \mathrm{~mm}, 0.18-0.5 \mathrm{~mm}, 0.075-0.18 \mathrm{~mm}$, and $<0.075 \mathrm{~mm}$, respectively). To remove the initial moisture content, crushed shale samples are oven-dried $\left(100{ }^{\circ} \mathrm{C}\right)$ under vacuum for 24 hours until to receive a constant sample weight. Water vapor adsorption measurements are conducted using an Aquadyne DVS-2 water sorption analyzer from Quantachrome, with a weight and relative humidity (RH) resolution of $0.1 \mu \mathrm{g}$ and $0.1 \%$. Approximately $1.5 \mathrm{bar}$ is maintained for the external gas inlet pressure. A schematic of the experimental setup is shown in Fig. 1. This instrument can gravimetrically determine water uptake during the adsorption (increasing $\mathrm{RH}$ ) and loss in the desorption processes (decreasing $\mathrm{RH}$ ) as a function of $\mathrm{RH}$, which is equivalent to the relative pressure. The desired RH is obtained by mixing the dry nitrogen and wetting nitrogen gas stream. In the adsorption process, water vapor equilibration is conducted at the low-humidity condition of 5\% RH and increases stepwise up to the maximum 95\% RH. In the subsequent desorption process, shale sample mass will decrease gradually from $95 \% \mathrm{RH}$ to $5 \% \mathrm{RH}$. An independent temperature of $60{ }^{\circ} \mathrm{C}$ is adopted in this work to control the balance head environment. Approximately 100-200 mg of shale samples are equilibrated in a sealed condition at a chamber temperature of $50{ }^{\circ} \mathrm{C}$ (with a temperature resolution of 0.2 ${ }^{\circ} \mathrm{C}$ ). The increase rate of $\mathrm{RH}$ is adopted as $1 \%$ per minute. Mass of water vapor uptake in shale at certain particular $\mathrm{RH}$ can be determined by calculating the differences between the mass of the dried and humidified shale sample. Finally, water vapor adsorption data collected on different shale size fractions are modeled using the GAB and Dent models to describe water vapor adsorption behaviors within shale.

\section{Theoretical background}

\subsection{Brunauer-Emmett-Teller (BET) theory}

As the most commonly utilized model for gas adsorption, 
the BET theory is based on a kinetic model of the adsorption mechanism proposed by Langmuir (1918), which assumes that solid surface is regarded as an array of identical adsorption sites and adsorption is limited to a monolayer. Compared to Langmuir model, BET theory extends from monolayer adsorption to multilayer adsorption, and assumes that the uppermost molecules in adsorbed stacks are in dynamic equilibrium with the vapor (Mooney et al., 1952; Gregg and Sing, 1982). When the surface is covered by only one layer of adsorbate, an equilibrium occurs between the adsorbed molecule and the vapor, which is similar with Langmuir model. When two or more layers have been adsorbed, the upper layer could provide new sites for adsorption, which is in equilibrium with the vapor, and so forth. BET theory assumes that the second and higher layers of molecules adsorbed are all equivalent to the liquid phase and the interaction energy of adsorbateadsorbate is equal to the heat of liquefaction (Mooney et al., 1952; Charrière and Behra, 2010). The BET equation can be expressed by the following equation:

$$
\frac{Q}{Q_{m o}}=\frac{C}{\left(1-\frac{p}{p_{0}}\right)\left(1-\frac{p}{p_{0}}+C \frac{p}{p_{0}}\right)} \frac{p}{p_{0}}
$$

where $Q$ is the adsorption capacity at pressure $p ; Q_{m o}$ is the BET monolayer adsorption capacity; $p_{o}$ is the saturation pressure; constant $C$ reflects the adsorption heat and is equal to $A \mathrm{e}^{\left(\left(E_{1}-E_{L}\right) / R T\right)}$, in which $A$ is a kinetic constant and $E_{1}$ is the adsorption energy at the first layer. $E_{L}$ represents the adsorption energy at other layers and equals to the heat of liquefaction (Charrière and Behra, 2010; Duan and Li, 2018); $T$ and $R$ are the temperature and gas content, respectively. BET equation is also widely applied to determine the surface area of porous materials within a RH range of 5\%-35\% (Kuila and Prasad, 2013; Thommes et al., 2015).

\subsection{Dent model}

For years, Dent's multilayer model has been utilized to simulate water sorption behavior in coal (Dent, 1977; Mccutcheon et al., 2003; Charrière and Behra, 2010; Tang et al., 2017; Duan and Li, 2018). Because both coal seam and shale are typical carbonaceous organic-rich porous rocks with many similar characteristics, Dent model is also used to fit water vapor adsorption in shale (Tang et al., 2017). Based on multilayer adsorption theory, Dent model assumes that water vapor adsorption occurs on the specific sites (primary and secondary adsorption sites) and adsorption state of water molecules beyond the first layers is the same but quite different to the pure liquid state (Dent, 1977; Timmermann, 2003). Considering that shale usually contains abundant inorganic-related (hydrophilic) and organic-hosted (hydrophobic) nanopores, thus the primary adsorption sites mainly refer to those specific adsorption sites on the inorganic surface wall with extremely high binding energies (Tang et al., 2017; Zhou et al., 2018). In contrast, secondary adsorption sites with relative weak binding energies include the bindings between water molecule and first layer water occupied on primary sites and water vapor adsorption on the layers beyond the first layer formed secondary sites (Charrière and Behra, 2010; Tang et al., 2017). Based on the BET theory and the presence of two adsorption sites, Dent model can be expressed as the following equation (Charrière and Behra, 2010):

$$
Q=\frac{Q_{M} K_{1}}{\left(1-K_{2} \frac{p}{p_{0}}\right)\left(1+K_{1} \frac{p}{p_{0}}-K_{2} \frac{p}{p_{0}}\right)} \frac{p}{p_{0}}
$$

where $Q_{M}$ is the monolayer adsorption capacity; $K_{1}$ and $K_{2}$ are constants related to the adsorption energies of the primary and secondary adsorption sites; and $p / p_{o}$ equals to the RH.

The quantity of adsorption on primary and secondary sites can be respectively calculated using the following equations (Charrière and Behra, 2010):

$$
\begin{gathered}
Q_{1}=\frac{Q_{M} K_{1} p}{1-K_{2} p+K_{1} p} \\
Q_{2}=\frac{Q_{M} K_{1} K_{2}\left(\frac{p}{p_{0}}\right)^{2}}{\left(1-K_{2} \frac{p}{p_{0}}\right)\left(1-K_{2} \frac{p}{p_{0}}+K_{1} \frac{p}{p_{0}}\right)}
\end{gathered}
$$

where the sum of $Q_{1}$ and $Q_{2}$ corresponds to the total amount of adsorption uptake $Q$; constants $K_{1}$ and $K_{2}$ are equal to $A \mathrm{e}^{\left(\left(E_{i}-E_{L}\right) / R T\right)}$, in which $E_{i}$ is the adsorption energy at the primary or secondary adsorption sites.

\subsection{GAB model}

Based on BET multilayer adsorption theory, Anderson (1946), Deboer (1953) and Guggenheim (1966) also developed a modified BET model (called as GAB model), which is widely used to describe the water vapor adsorption on solid surfaces (e.g., activated carbon, alumina, silica and coal). In practice, shale rocks are known to be heterogeneous porous materials and do not have an ideal pore surface for the BET model. Compared to BET theory, GAB model assumes that the interactions between adsorbed water molecules are different from that between water molecules with a bulk phase. By introducing another adsorption parameter $(K)$ in the equation, GAB model improves the applicability of BET model and its activity range covered by the adsorption isotherm is much wider with RH values varying from 5\% to $95 \%$ (Timmermann, 2003). The GAB model can be expressed using the following equation (Gasparik et al., 2014):

$$
Q=\frac{Q_{m} C_{G A B} K}{\left(1-K \frac{p}{p_{0}}\right)\left[1+\left(C_{G A B}-1\right) K \frac{p}{p_{0}}\right]} \frac{p}{p_{0}}
$$

where $Q_{m}$ is the GAB monolayer capacity; $C_{G A B}$ is a constant related to the heat of adsorption; and $K$ is a constant related to the adsorption energies of multilayer adsorption sites. Particularly, when parameter $K$ equals 1, GAB model is reduced to the original BET equation. Using the least-squares method to fit the experimental data, the parameters $Q_{m}, C_{G A B}$ and $K$ can be determined (Shen et al., 2018). 

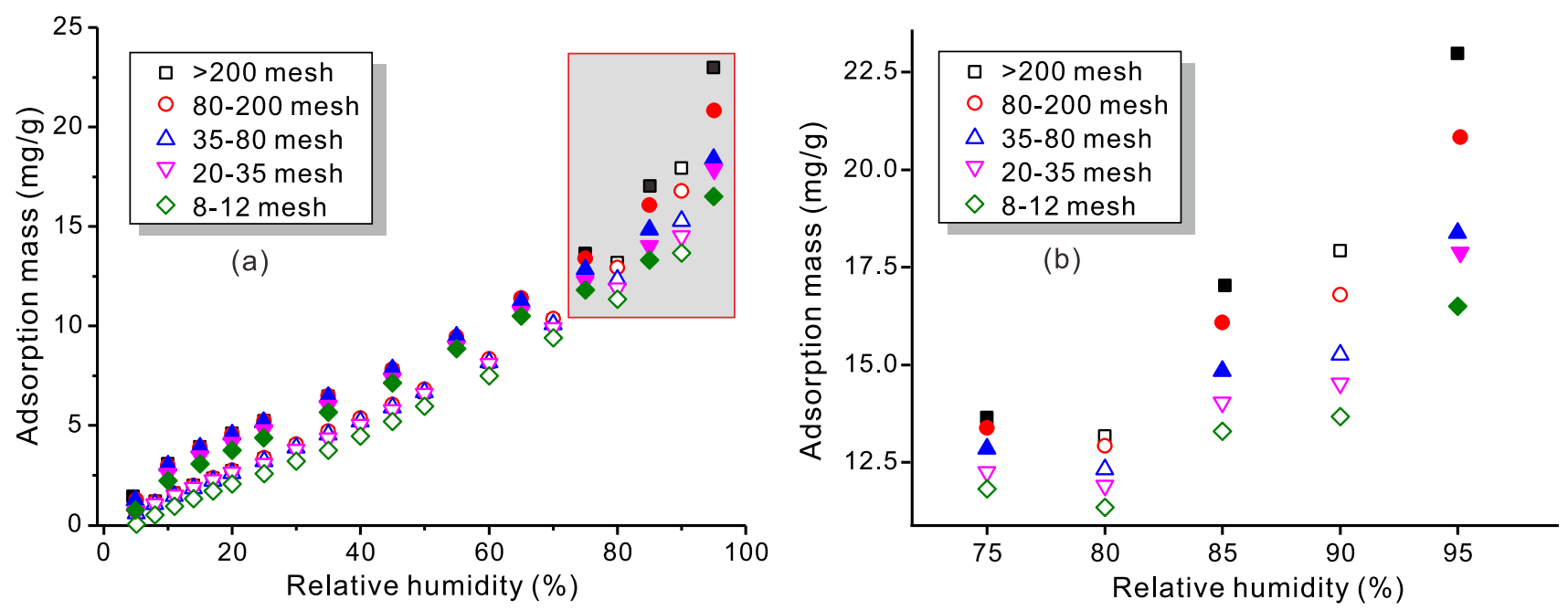

Fig. 2. Water vapor adsorption (open symbol) and desorption (solid symbol) uptake versus relative humility at $50{ }^{\circ} \mathrm{C}$ for different shale size fractions. (a) the adsorption/desorption curves in the entire RH range; (b) Enlarged view of the red box in Fig. 2(a).

\section{Results and discussion}

\subsection{Effect of particle size on water sorption isotherm}

The measured water vapor adsorption isotherms for shale samples with different particle sizes are exhibited in Fig. 2. According to the International Union of Pure and Applied Chemistry (IUPAC) classification of sorption isotherms (Sing, 1985), all the water vapor adsorption isotherms have similar curve shape and belong to the type II isotherm (Fig. 2(a)). Compared to typical type II isotherm, less distinctive inflection point is observed, which could be an indication of the overlap of monolayer coverage and the beginning of multilayer adsorption (Thommes et al., 2015). Fig. 2(a) shows that the equilibrium moisture contents of different shale size fractions increase with $\mathrm{RH}$ and reaches the highest adsorption uptakes at the end of RH. The maximum uptake of water vapor adsorption at the end of $\mathrm{RH}$ gradually decrease from 22.98 $\mathrm{mg} / \mathrm{g}$ for $>200$ mesh fraction to $16.50 \mathrm{mg} / \mathrm{g}$ for $8-12$ mesh fraction (Table 2), suggesting that less water is adsorbed in the sample with the larger particle size. Generally, two bending regions are observed in the adsorption curves, with one at RH around 20\% and another at around 70\% RH. Therefore, the water vapor isotherms can be generally divided into three regions (region 1 with $\mathrm{RH}<20 \%$, region 2 with $\mathrm{RH}$ of $20 \%$ $70 \%$ and region 3 with $\mathrm{RH}>70 \%$ ), which could correspond to different adsorption mechanisms (Tang et al., 2017; Duan and Li, 2018; Sang et al., 2019). In region 1 with a low RH, minimal water is adsorbed on the pore surfaces, with most being adsorbed at the primary adsorption sites by the van der Waals force and oxygen-containing groups by hydrogen bonding. In region 2 , water vapor uptake generally increases linearly and multilayer adsorption occurs above the monolayer sites, which has been documented in previous studies (Shen et al., 2018; Sang et al., 2019). In region 3, excess water could have adsorbed at the remaining secondary sites (including hydrophilic and hydrophobic sites) in larger pores to form water clusters, which is gradually controlled by capillary condensation (Ferrage et al., 2005; Cailliez et al., 2008).

The comparison of moisture isotherms obtained at different particle sizes also show that, when the $\mathrm{RH}$ value is smaller than approximately $70 \%$, adsorbed water mass in shales with different particle sizes is very close. However, the coarsest fraction (8-12 mesh) is an exception, which shows a smaller adsorption mass than other fractions at the same RH. When the RH is larger than approximately $70 \%$, a significant variation for water vapor adsorption mass among different shale size fractions, and the amount of water uptake increase as particle size decreases (Fig. 2(b)). Fig. 2(b) shows that shale samples with smaller particle size can adsorb more water. Previous studies on nitrogen physisorption show that samples with smaller particle size fractions can elevate measured micropore and mesopore volumes, due to the possible increase of accessible of pores to gases (Chen et al., 2015; Han et al., 2016; Mastalerz et al., 2017). However, the micorporosity in shale is speculated to be not significantly affected by manual mild crushing and sieving, which may account for the similar amount of water uptake at low RH. However, when samples with larger particle size, the sample porosity is lower and the connectivity of the pore system could become worse ( $\mathrm{Li}$ et al., 2019b). Scanning electron microscope (SEM) shows that the pore network of shale has some larger mineralrelated and organic matter-hosted meso-macropores (Zhang et al., 2017; Yang et al., 2019); however, these pores are mainly connected by multiple micorpores, which could restrict water molecular migration due to the high capillary force. In addition, shale contains both abundant inorganic (hydrophilic) and organic (hydrophobic) micropores; thus, water molecules will preferentially be adsorbed on the primary adsorption sites from hydrophilic inorganic pores (with strong binding energy) at low RH. The combined effects of pores with different wettability characteristics and water-selective access to pore system may also result in a slightly smaller water vapor uptake in the sample with a larger particle size. 
Table 2. GAB modelling results of water vapor adsorption/desorption for shale sample with different particle sizes. AHI $=$ Areal hysteresis index.

\begin{tabular}{|c|c|c|c|c|c|c|c|c|c|c|}
\hline \multirow{2}{*}{ Parameters } & \multicolumn{2}{|c|}{$>200$ mesh } & \multicolumn{2}{|c|}{ 80-200 mesh } & \multicolumn{2}{|c|}{$35-80$ mesh } & \multicolumn{2}{|c|}{ 20-35 mesh } & \multicolumn{2}{|c|}{ 8-12 mesh } \\
\hline & Adsorption & Desorption & Adsorption & Desorption & Adsorption & Desorption & Adsorption & Desorption & Adsorption & Desorption \\
\hline$Q_{m}(\mathrm{~g} / \mathrm{g})$ & 0.0049 & 0.00597 & 0.0055 & 0.0067 & 0.0064 & 0.0073 & 0.0062 & 0.0072 & 0.0089 & 0.0084 \\
\hline$C_{G A B}$ & 4.6203 & 9.79977 & 4.0406 & 8.1000 & 3.2504 & 7.6556 & 3.3614 & 6.2758 & 1.7478 & 4.8335 \\
\hline K & 0.8388 & 0.78749 & 0.7896 & 0.7312 & 0.7242 & 0.6619 & 0.7203 & 0.6588 & 0.6289 & 0.5849 \\
\hline Adj. R-Square & 0.99869 & 0.9996 & 0.99866 & 0.9988 & 0.99859 & 0.99811 & 0.99726 & 0.99582 & 0.99674 & 0.99656 \\
\hline Reduced Chi-Sqr & $\begin{array}{l}5.086 \\
\times 10^{-8}\end{array}$ & $\begin{array}{l}1.638 \\
\times 10^{-8}\end{array}$ & $\begin{array}{l}4.437 \\
\times 10^{-8}\end{array}$ & $\begin{array}{l}4.133 \\
\times 10^{-8}\end{array}$ & $\begin{array}{l}3.834 \\
\times 10^{-8}\end{array}$ & $\begin{array}{l}5.147 \\
\times 10^{-8}\end{array}$ & $\begin{array}{l}6.880 \\
\times 10^{-8}\end{array}$ & $\begin{array}{l}1.116 \\
\times 10^{-8}\end{array}$ & $\begin{array}{l}7.689 \\
\times 10^{-8}\end{array}$ & $\begin{array}{l}8.275 \\
\times 10^{-8}\end{array}$ \\
\hline $\mathrm{AHI}(\%)$ & \multicolumn{2}{|c|}{21.48} & \multicolumn{2}{|c|}{22.12} & \multicolumn{2}{|c|}{23.62} & \multicolumn{2}{|c|}{19.67} & \multicolumn{2}{|c|}{24.74} \\
\hline $\begin{array}{l}\text { Maximum water } \\
\text { vapor adsorption } \\
(\mathrm{mg} / \mathrm{g})\end{array}$ & \multicolumn{2}{|c|}{22.98} & \multicolumn{2}{|c|}{20.83} & \multicolumn{2}{|c|}{18.38} & \multicolumn{2}{|c|}{17.88} & \multicolumn{2}{|c|}{16.50} \\
\hline
\end{tabular}
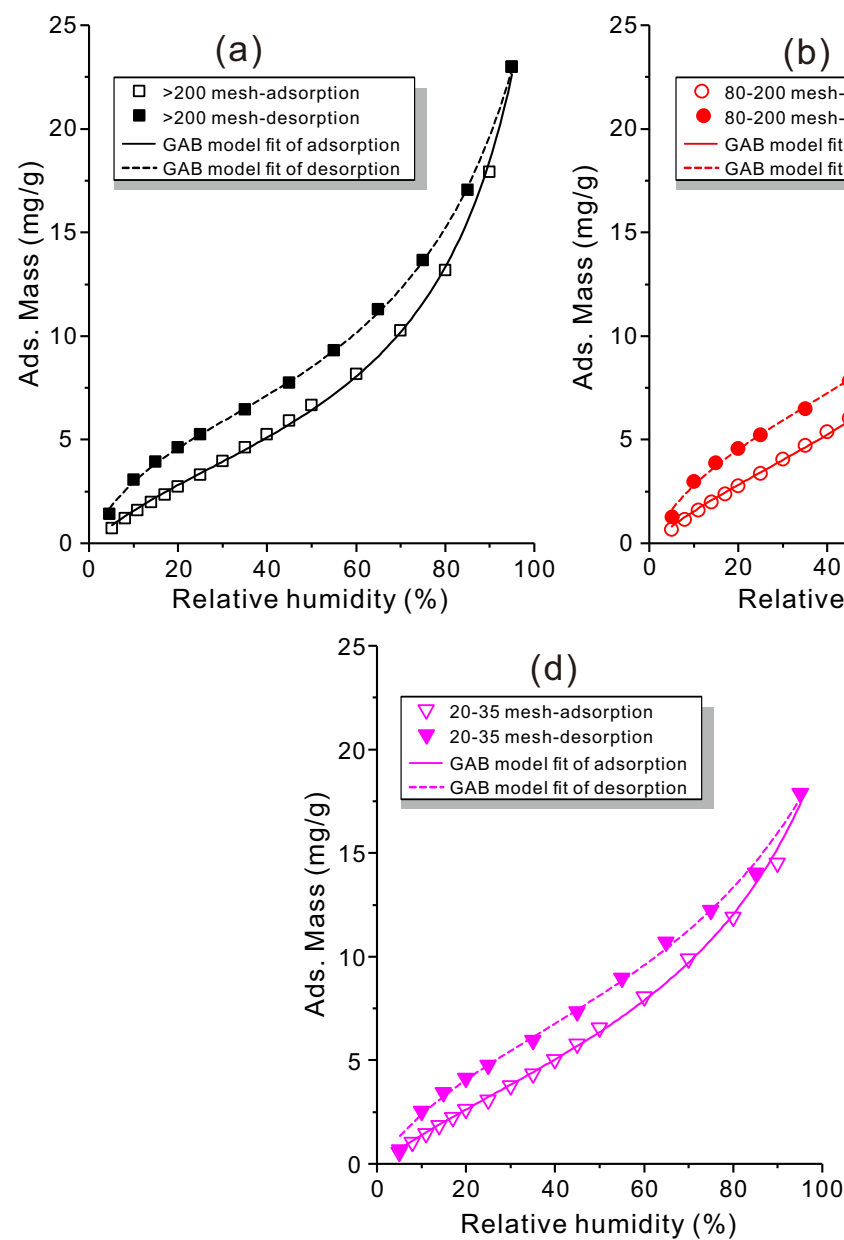

(b)
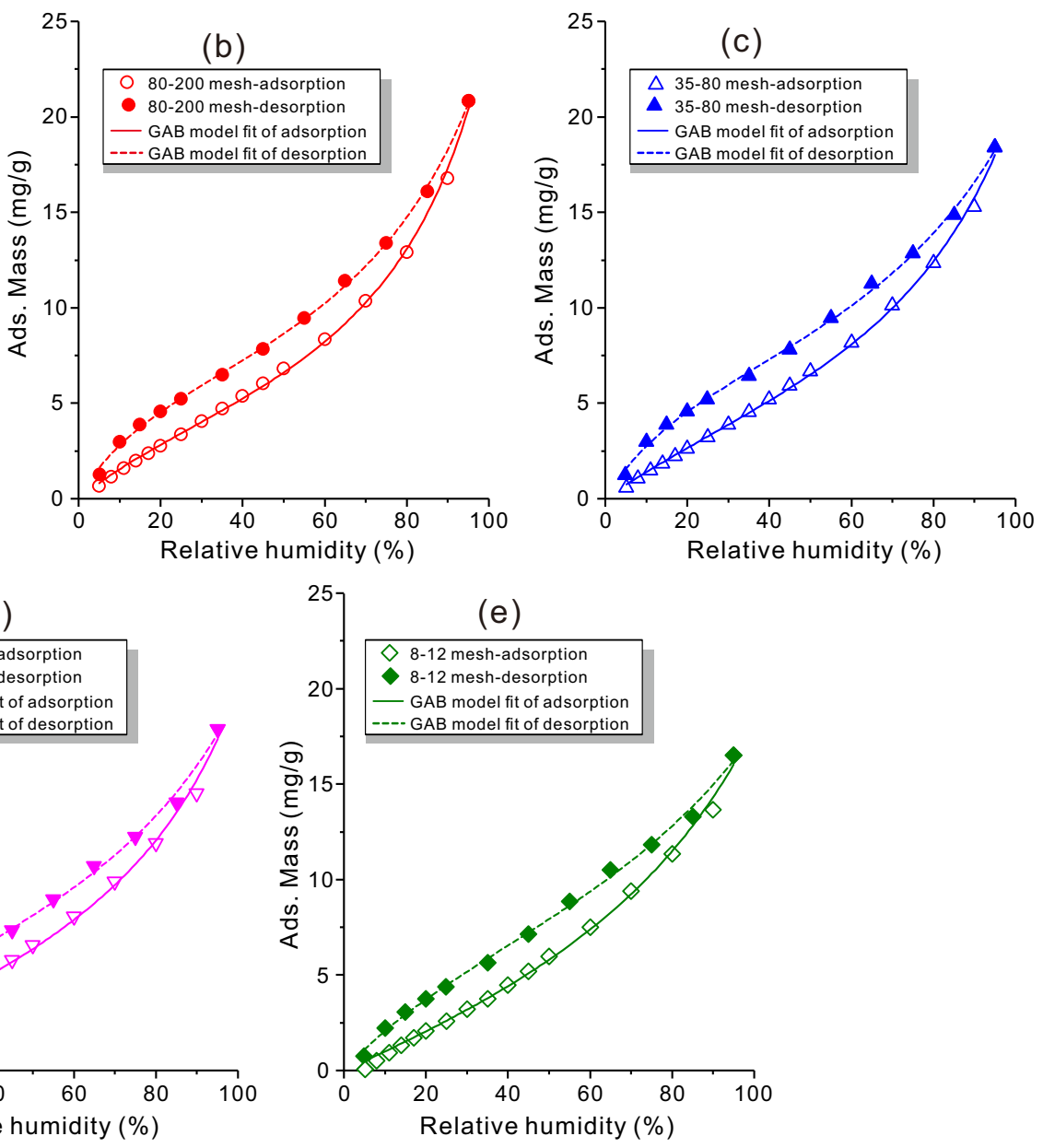

Fig. 3. Fitting of experimental moisture adsorption and desorption data using GAB model for shale with different particle sizes. 


\subsection{Effect of particle size on the hysteresis loop}

In this work, three-parameter GAB model is used to fit the water vapor adsorption/desorption data and the fitting results are shown in Fig. 3. The fitting curve and constants included in the $\mathrm{GAB}$ equation are determined using nonlinear regression analysis by finding least-squares fits to the experimental data (Table 2). Fig. 3 shows good fitting results of both the experimental data (adsorption and desorption) for shale with different particle sizes, with all the Adjusted R-Square values being larger than 0.99 . Results show that $Q_{m}$ values obtained from water vapor adsorption data gradually increase from 4.9 $\mathrm{mg} / \mathrm{g}$ in $>200$ mesh fraction to $8.9 \mathrm{mg} / \mathrm{g}$ in $8-12$ mesh fraction (Table 2). Similar increase trend for $Q_{m}$ values determined from water desorption data is observed, suggesting that the adsorption potential and amount of water uptake adsorbed to specific sites at shale surface become stronger as the sample particle size increases. In contrast, $C_{G A B}$ and $K$ show a reverse relationship for both adsorption and desorption data when particle size increases, indicating the possible variation of pore surface properties for different fractions. All the $K$ values are smaller than 1.0, suggesting the adsorption on the secondary sites is weaker than that on the primary adsorption sites and the heat of multilayer adsorption of water molecules is smaller than the heat of liquefaction (Arthur et al., 2018).

Fig. 3 shows that significant differences between the adsorption/desorption branches (refer as hysteresis loops), which is similar as that observed in gas physisorption (Yang et al., 2016, 2017; Guo et al., 2019). According to the IUPAC classification (Sing, 1985), the shape of hysteresis loops shown in Fig. 3 can be categorized as type H3, which is often associated with slit-shaped pores. Relationship between hysteretic loop curves versus RH for shale samples with different particle sizes shows a bimodal distribution with the peak at $\mathrm{RH}$ values of around $20 \%$ and $70 \%$ (Fig. 4). With the increase of RH, the hysteretic degree for different mesh fractions varies, which could be related to different mechanisms for the occurrence of hysteretic loop at various $\mathrm{RH}$. When the $\mathrm{RH}$ is smaller than approximately 35\%, 35-80 mesh fraction has the largest magnitude of hysteretic loop, while 20-35 mesh fraction has the smallest. This may be associated with the complex pore structure of shale, which contains some constricted micropores with narrow pore throats and water molecule is adsorbed on those primary adsorption sites by strong bonding energy. Compared to adsorption at the same $\mathrm{RH}$, fewer water molecules can be escaped from these adsorption sites with high binding energy during the desorption process. Thus, the occurrence of hysteretic loop in this RH range could be related to the physical in connectivity and accessibility between adsorption pores. This is often caused by the swelling and shrinkage effect of shale matrix, irreversible adsorption of water in micropore spaces by strong interaction, and the possible chemical interaction between water and shale (Kai et al., 2014; Tang et al., 2017; Zhang and Liu, 2017). In the range of 35\%-65\% RH, 8-12 mesh and 20-35 mesh fractions respectively have the largest and smallest magnitude of hysteretic loop, which may be related to different degrees of multilayer adsorption and capillary condensation in mesopore spaces (Sang et al.,

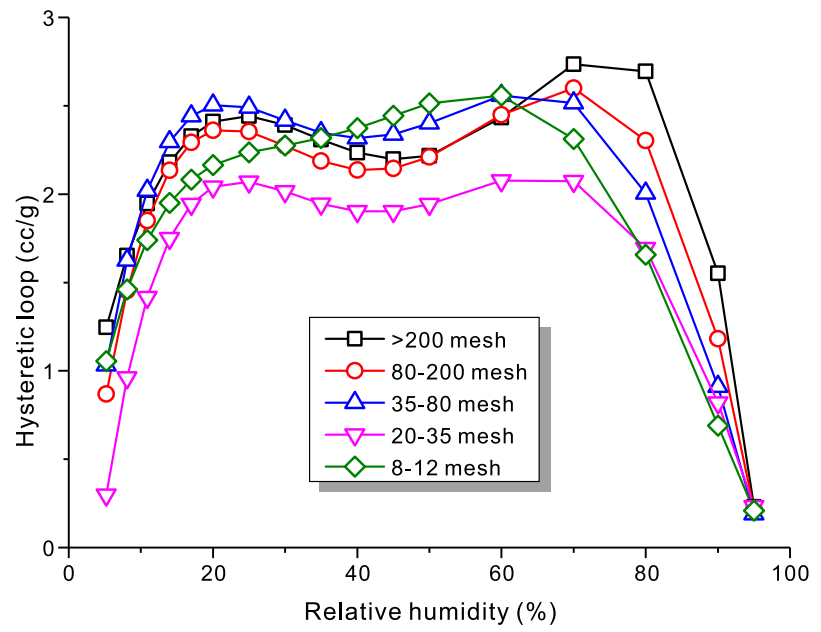

Fig. 4. Correlation between hysteretic loop curves versus relative humility for shale samples with different particle sizes.

2019). When RH increases further, the magnitude of hysteretic loop generally follows the order: $>200$ mesh $>80-200$ mesh $>35-80$ mesh $>20-35$ mesh $>8-12$ mesh, suggesting that hysteretic loops become smaller as the particle size increases at high RH (e.g., > 80\% RH). During the process of adsorption in mesopore spaces (especially in some bottleneck pores), capillary condensation often occurs in the neck of the pores, which can limit the pore filling by the water molecules in the pore body (Charrière and Behra, 2010). However, during the desorption process, adsorbed water molecules in the neck of ink-bottle shaped pores can be desorbed while water molecules in the pore body are retained, resulting in the development of hysteresis loops at high RH (Mccutcheon et al., 2003; Kai et al., 2014; Chen et al., 2017). In addition, tensile strength effect of the adsorbed phase could also account for the observed hysteresis loops at high RH (Puri et al., 1961; Gregg and Sing, 1982; Tang et al., 2017).

Hysteresis index (HI) are widely applied to quantitatively characterize the degree of hysteresis loops between water vapor adsorption and desorption isotherms (Sander et al., 2005; Kai et al., 2014; Tang et al., 2017; Zhang and Liu, 2017). Many methods of $\mathrm{HI}$ have been proposed in the literature, which relies on the variables, such as adsorptive concentration, apparent distribution coefficient, area or slop between addesorption isotherm, and Freundlich exponent (Sander et al., 2005; Kai et al., 2014). Among them, areal hysteresis index (AHI) is one of the commonly used methods to characterize the hysteresis loop. AHI value can be determined using the following equation:

$$
A H I=\frac{A_{d e}-A_{a d}}{A_{a d}} \times 100 \%
$$

where $A_{a d}$ and $A_{d e}$ are the area under the adsorption and desorption isotherm, respectively; thus, AHI is the ratio of the hysteresis loops area $\left(A_{d e}-A_{a d}\right)$ to the area of adsorption isotherm.

Using the Eq. (6), the AHI values are calculated based on the GAB modelled adsorption and desorption isotherms (Table 2). Overall, AHI values increase for the sample with a 

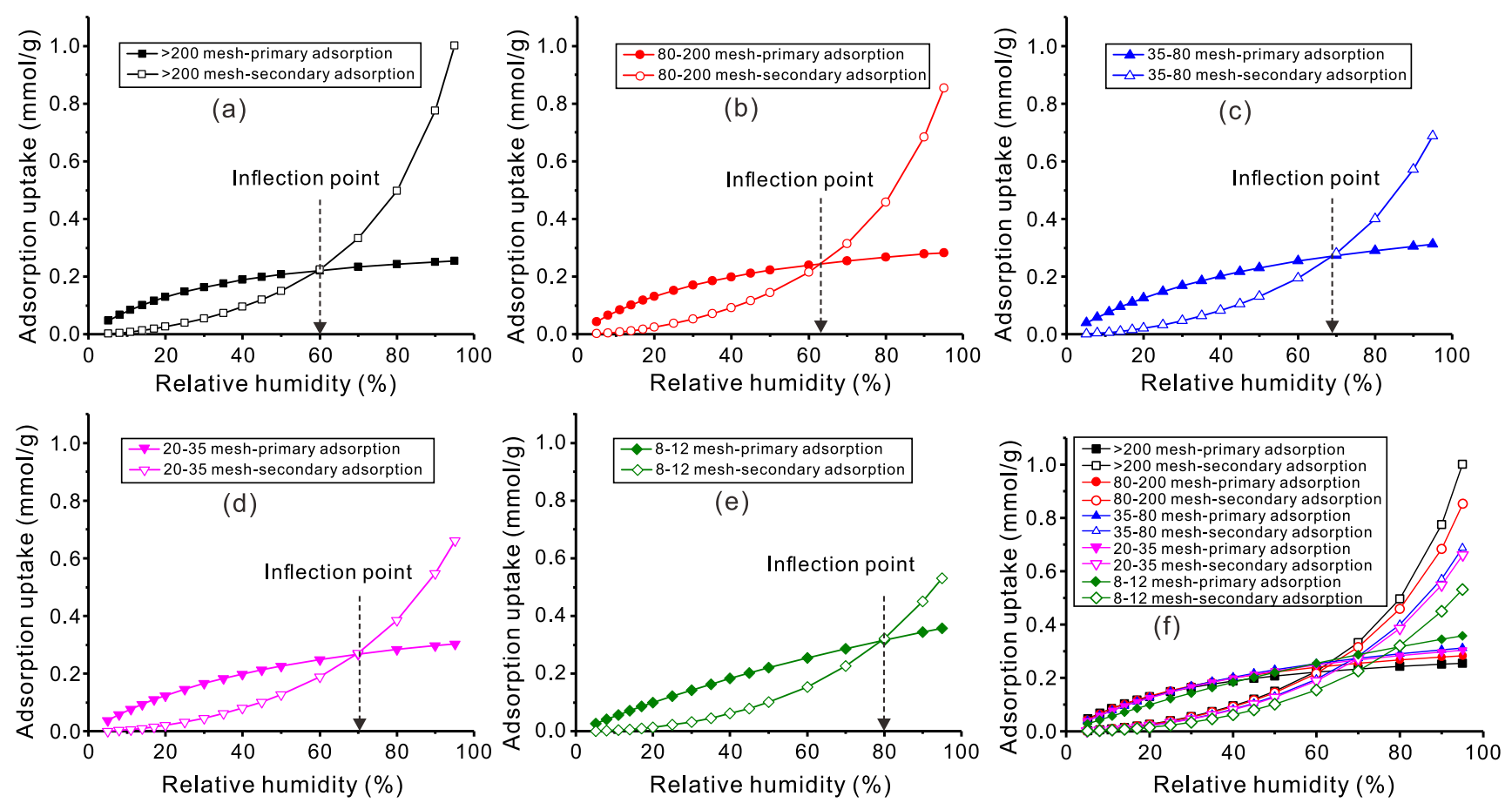

Fig. 5. The water vapor adsorption capacity on the primary and secondary sites for the shales with different particle sizes.

Table 3. Dent modelling results of water vapor adsorption for shale sample with different particle sizes.

\begin{tabular}{llllll}
\hline Parameters & $>200$ mesh & $80-200$ mesh & $35-80$ mesh & $20-35$ mesh & $8-12$ mesh \\
\hline$Q_{M}(\mathrm{mmol} / \mathrm{g})$ & 0.2691 & 0.3062 & 0.3553 & 0.3456 & 0.4962 \\
$K_{1}$ & 3.8766 & 3.1906 & 2.354 & 2.4212 & 1.0989 \\
$K_{2}$ & 0.8389 & 0.7896 & 0.7243 & 0.7203 & 0.6289 \\
Adj. R-Square & 0.99869 & 0.99866 & 0.99859 & 0.99726 & 0.99674 \\
Reduced Chi-Sqr & $1.568 \times 10^{-4}$ & $1.363 \times 10^{-4}$ & $1.181 \times 10^{-4}$ & $2.121 \times 10^{-4}$ & $2.369 \times 10^{-4}$ \\
$E_{1}(\mathrm{~kJ} / \mathrm{mol})$ & 47.63 & 47.11 & 46.29 & 46.37 & 44.24 \\
$E_{2}(\mathrm{~kJ} / \mathrm{mol})$ & 43.52 & 43.36 & 43.12 & 43.11 & 42.74 \\
\hline
\end{tabular}

larger particle size, from $21.48 \%$ for $>200$ mesh fraction to $24.74 \%$ for $8-12$ mesh fraction, suggesting that shale sample with larger particle size trends to have a higher sorption hysteresis. Considering that the accessibility of pore system can become better as the grain size decrease; thus, some possible closed pores can open and pore connectivity could have been improved for the sample with a smaller particle size. It is also noted that 20-35 mesh fraction is an exception, which has the lowest AHI value of $19.67 \%$, suggesting that more adsorbed water molecules have desorbed when RH decreases. In addition, coarsest sample often needs a longer time to reach moisture equilibrium; thus, 20-35 mesh fraction is suggested to be the optimum particle size for comparative purpose of sorption measurements.

\subsection{Effect of particle size on primary and secondary adsorption capacity}

Using the Dent model, water vapor adsorption capacity on the primary and secondary sites for different shale size fractions are determined (Fig. 5) and related parameters $\left(Q_{M}\right.$, $K_{1}, K_{2}, E_{1}$ and $\left.E_{2}\right)$ are given in Table 3. The values of Adj. R-Square and Reduced Chi-Sqr suggest a good fitting accuracy. Table 3 show that all the $K_{1}$ and $E_{1}$ values from each fraction are larger than the corresponding $K_{2}$ and $E_{2}$ values, suggesting that more energy is needed for the weak interaction of water-shale matrix than the strong interaction of water-water molecules.

Fig. 6 shows the ratios of water vapor adsorption capacity at primary adsorption sites to secondary ones in shale samples with different particle sizes. Overall, similar relationships between ratios of water vapor adsorption capacity at primary sites to the secondary sites and RH (Fig. 6(a)) or pressure (Fig. 6(b)). As the RH or pressure values increase, the ratios of water vapor adsorption capacity at primary adsorption sites to secondary adsorption sites decrease rapidly (a factor of greater than 50) from 21.92 to 0.25 for $>200$ mesh fraction, from 24.33 to 0.33 for $80-200$ mesh fraction, from 26.07 to 0.45 

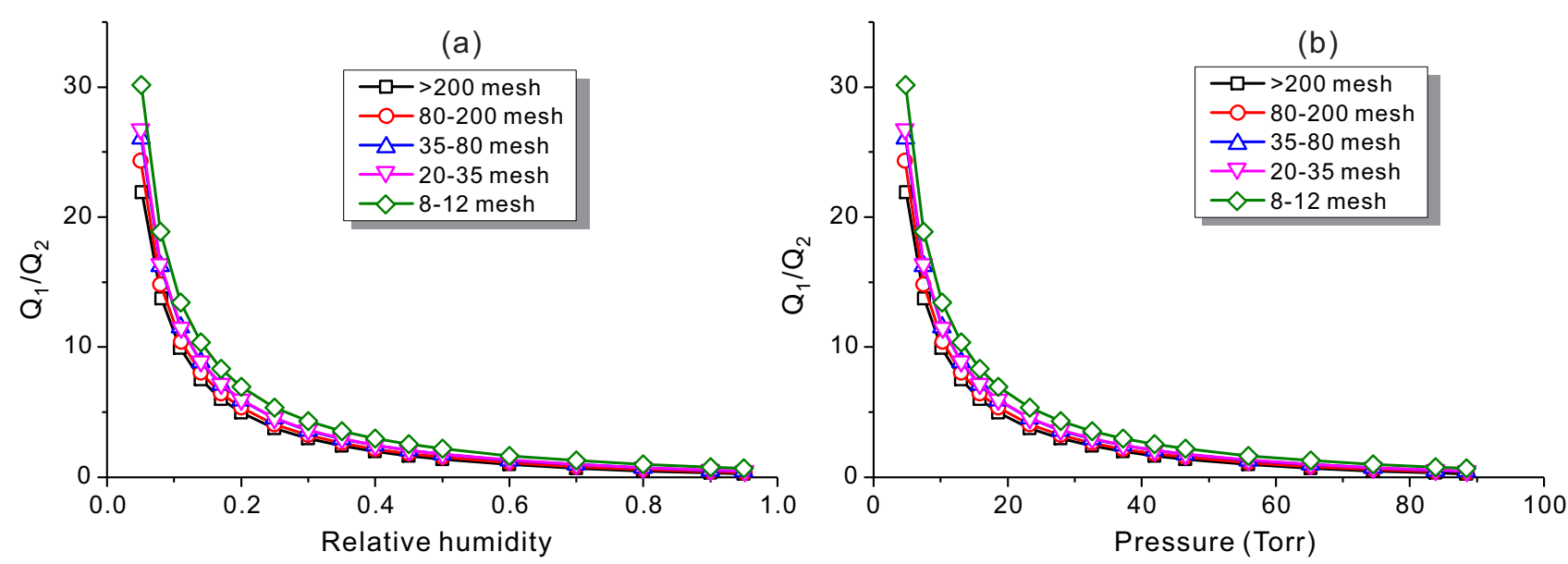

Fig. 6. The ratio of the water vapor adsorption capacity at primary adsorption site to the secondary adsorption site in shale samples with different particle sizes.

for 35-80 mesh, from 26.77 to 0.46 for 20-35 mesh and from 30.18 to 0.67 . In addition, the ratios of adsorption capacity at primary adsorption sites to secondary ones at the same $\mathrm{RH}$ or pressure increases slightly as the particle size increases, suggesting that the monolayer capacity is larger in the coarsest shale sample.

\section{Conclusions}

In this work, water vapor adsorption measurement on one organic Dongyuemiao shale of Lower Jurassic Ziliujing Formation in Jiannan Area with different particle sizes are conducted over a wide $\mathrm{RH}$ range (5\%-95\%) and the particle size effects on water vapor sorption of shale are discussed. The main conclusions can be summarized as follows:

1) Maximum uptake of water vapor adsorption decreases from $22.98 \mathrm{mg} / \mathrm{g}$ for $>200$ mesh fraction to $16.50 \mathrm{mg} / \mathrm{g}$ for 8-12 mesh fraction, suggesting that less water is adsorbed in the sample with a larger particle size. When $\mathrm{RH}$ value is smaller than approximately $70 \%$, water vapor mass in shales with different particle sizes is very close, but increase as particle size decreases, which could be related to the possible variation of accessible pores.

2) GAB model fitting results show that $Q_{m}$ values obtained from water vapor adsorption data gradually increase from $4.9 \mathrm{mg} / \mathrm{g}$ in $>200$ mesh fraction to $8.9 \mathrm{mg} / \mathrm{g}$ in $8-12$ mesh fraction, suggesting that the adsorption potential and amount of water adsorbed to specific sites at shale surface become stronger as sample particle size increases. The shapes of hysteresis loops are categorized as type $\mathrm{H} 3$, and a bimodal distribution for different shale size fractions are observed in the plot between hysteretic loop curves versus $\mathrm{RH}$ with the peak at around $20 \%$ RH and 70\% RH. Except for 20-35 mesh fraction, AHI values increase with the increasing of sample particle size, suggesting that shale sample with larger particle size tends to have a higher sorption hysteresis. Comparative studies show that 20-35 mesh fraction is suggested to be the optimum particle size for comparative purpose.

3) Water vapor adsorption on primary sites are similar to type I isotherm, showing monolayer adsorption characteristics, while type III for adsorption on secondary sites, which is associated with multilayer adsorption. Water vapor adsorption on the primary sites dominates when RH value is smaller than approximately $60 \%-80 \%$, which is excessed by adsorptions on secondary sites after that. With the increase of particle size, adsorption uptake on the primary sites increase slightly. A decrease trend is observed for water vapor adsorption on the secondary sites as particle size increases, which could be related to smaller surface area to provide less adsorption sites.

\section{Acknowledgement}

We thank the following sponsors for financial assistance to this research: National Natural Science Foundation of China (Nos. 41830431, 41902140), and Open Foundation of Key Laboratory of Tectonics and Petroleum Resources, Ministry of Education, China University of Geosciences (No. TPR-201902). We thank Sinpec Jianghan Oilfield Branch Company for providing the core sample for this study. We appreciate the enthusiastic support of Xiang Lin and Gang Wang from China University of Geosciences (Wuhan) for their guidance on water adsorption tests.

\section{Conflict of interest}

The authors declare no competing interest.

Open Access This article, published at Ausasia Science and Technology Press on behalf of the Division of Porous Flow, Hubei Province Society of Rock Mechanics and Engineering, is distributed under the terms and conditions of the Creative Commons Attribution (CC BY-NC-ND) license, which permits unrestricted use, distribution, and reproduction in any medium, provided the original work is properly cited.

\section{References}

Adam, E., Mühlbaucr, W., Esper, A., et al. Effect of temperature on water sorption equilibrium of onion (Allium Cepa L). Dry. Technol. 2000, 18(9): 2117-2129.

Anderson, R.B. Modifications of the brunauer, emmett and 
teller equation. J. Am. Chem. Soc. 1946, 68(4): 686-691. Arthur, E., Tuller, M., Moldrup, P., et al. Applicability of the Guggenheim-Anderson-Boer water vapour sorption model for estimation of soil specific surface area. Eur. J. Soil Sci. 2018, 69(2): 245-255.

Barton, S.S., Evans, M.J.B., Macdonald, J.A.F. The adsorption of water vapor by porous carbon. Carbon 1991, 29(8): 1099-1105.

Cai, J., Li, C., Song, K., et al. The influence of salinity and mineral components on spontaneous imbibition in tight sandstone. Fuel 2020, 269: 117087.

Cai, J., Wei, W., Hu, X., et al. Electrical conductivity models in saturated porous media: A review. Earth-Sci. Rev. 2017, 171: 419-433.

Cai, J., Yu, B. Prediction of maximum pore size of porous media based on fractal geometry. Fractals 2010, 18(4): 417-423.

Cailliez, F., Stirnemann, G., Boutin, A., et al. Does water condense in hydrophobic cavities? A molecular simulation study of hydration in heterogeneous nanopores. J. Phys. Chem. C 2008, 112(28): 10435-10445.

Charrière, D., Behra, P. Water sorption on coals. J. Colloid Interface Sci. 2010, 344(2): 460-467.

Chen, J., Wang, F., Liu, H., et al. Molecular mechanism of adsorption/desorption hysteresis: Dynamics of shale gas in nanopores. Sci. China-Phys. Mech. Astron. 2017, 60(1): 014611.

Chen, Y., Wei, L., Mastalerz, M., et al. The effect of analytical particle size on gas adsorption porosimetry of shale. Int. J. Coal Geol. 2015, 138: 103-112.

Chenevert, M.E. Shale alteration by water adsorption. J. Pet. Technol. 1970, 22(9): 1141-1148.

Deboer, J.H. The Dynamical Character of Adsorption. Oxford, UK, Clarendon Press, 1953.

Dent, R.W. A multilayer theory for gas sorption part I: Sorption of a single gas. Text. Res. J. 1977, 47(2): 145152.

Do, D., Do, H. A model for water adsorption in activated carbon. Carbon 2000, 38(5): 767-773.

Duan, S., Li, G. Equilibrium and kinetics of water vapor adsorption on shale. J. Energy Res. Technol. 2018, 140(12): 122001-122010.

EIA. Annual energy outlook 2018 with projections to 2050, 2018.

Feng, D., Li, X., Wang, X., et al. Water adsorption and its impact on the pore structure characteristics of shale clay. Appl. Clay Sci. 2018, 155(4): 126-138.

Ferrage, E., Lanson, B., Sakharov, B.A., et al. Investigation of smectite hydration properties by modeling experimental X-ray diffraction patterns: Part I. Montmorillonite hydration properties. Am. Miner. 2005, 90(8-9): 13581374.

Gasparik, M., Bertier, P., Gensterblum, Y., et al. Geological controls on the methane storage capacity in organic-rich shales. Int. J. Coal Geol. 2014, 123: 34-51.

Ghanbari, E., Dehghanpour, H. The fate of fracturing water: A field and simulation study. Fuel 2016, 163(1): 282-294.
Gregg, S.J., Sing, K.S.W. Adsorption, Surface Area and Porosity, Second Edition. London, UK, Academic Press, 1982.

Guggenheim, E.A. Applications of Statistical Mechanics. Oxford, UK, Oxford University Press, 1966.

Guo, X., Qin, Z., Yang, R., et al. Comparison of pore systems of clay-rich and silica-rich gas shales in the lower Silurian Longmaxi formation from the Jiaoshiba area in the eastern Sichuan Basin, China. Mar. Pet. Geol. 2019, 101(3): 265-280.

Han, H., Cao, Y., Chen, S., et al. Influence of particle size on gas-adsorption experiments of shales: An example from a Longmaxi Shale sample from the Sichuan Basin, China. Fuel 2016, 186: 750-757.

Han, H., Pang, P., Zhong, N., et al. The pore characteristics and gas potential of the Jurassic continental shales in the middle-small basins, northwest China. J. Pet. Sci. Eng. 2020, 188: 106873.

Hatch, C.D., Wiese, J.S., Crane, C.C., et al. Water adsorption on clay minerals as a function of relative humidity: Application of BET and freundlich adsorption models. Langmuir 2012, 28(3): 1790-1803.

Hughes, J.D. Energy: A reality check on the shale revolution. Nature 2013, 494(7437): 307-308.

Inagaki, S., Fukushima, Y., Kuroda, K., et al. Adsorption isotherm of water vapor and its large hysteresis on highly ordered mesoporous silica. J. Colloid Interface Sci. 1996, 180(2): 623-624.

Ji, L., Zhang, T., Milliken, K.L., et al. Experimental investigation of main controls to methane adsorption in clay-rich rocks. Appl. Geochem. 2012, 27(12): 25332545.

Joubert, J.I., Grein, C.T., Bienstock, D. Effect of moisture on the methane capacity of American coals. Fuel 1974, 53(3): 186-191.

Kai, W., Wang, G., Ren, T., et al. Methane and $\mathrm{CO}_{2}$ sorption hysteresis on coal: A critical review. Int. J. Coal Geol. 2014, 132: 60-80.

Kim, J.H., Lee, C.H., Kim, W.S., et al. Adsorption equilibria of water vapor on alumina, zeolite $13 \mathrm{X}$, and a zeolite X/activated carbon composite. J. Chem. Eng. Data 2003, 48(1): 137-141.

Kimura, T., Yamauchi, Y. Water sorption property controlled by nanoscale pore connectivity of large-sized cage-type mesopores. J. Nanosci. Nanotechnol. 2016, 16(9): 93079310.

King, G.E. Hydraulic fracturing 101: What every representative, environmentalist, regulator, reporter, investor, university researcher, neighbor and engineer should know about estimating frac risk and improving frac performance in unconventional gas and oil wells. Paper SPE 152596 Presented at SPE Hydraulic Fracturing Technology Conference, The Woodlans, Texas, 6-8 February, 2012.

Kuila, U., Prasad, M. Specific surface area and pore-size distribution in clays and shales. Geophys. Prospect. 2013, 61(2): 341-362. 
Langmuir, I. The adsorption of gases on plane surfaces of glass, mica and platinum. J. Am. Chem. Soc. 1918, 40(9): 1361-1403.

Li, J., Li, X., Wu, K., et al. Water sorption and distribution characteristics in clay and shale: Effect of surface force. Energy Fuels 2016, 30(11): 8863-8874.

Li, J., Wang, S., Lu, S., et al. Microdistribution and mobility of water in gas shale: A theoretical and experimental study. Mar. Pet. Geol. 2019a, 102: 496-507.

Li, J., Zhang, P., Lu, S., et al. Scale-dependent nature of porosity and pore size distribution in lacustrine shales: An investigation by BIB-SEM and x-ray CT methods. J. Earth Sci. 2019b, 30(4): 823-833.

Li, X., Krooss, B.M. Influence of grain size and moisture content on the high-pressure methane sorption capacity of Kimmeridge clay. Energy Fuels 2017, 31(11): 1154811557.

Liu, B., Yang, Y., Li, J., et al. Stress sensitivity of tight reservoirs and its effect on oil saturation: A case study of Lower Cretaceous tight clastic reservoirs in the Hailar Basin, Northeast China. J. Pet. Sci. Eng. 2020, 184: 106484.

Loucks, R.G., Reed, R.M., Ruppel, S.C., et al. Morphology, genesis, and distribution of nanometer-scale pores in siliceous mudstones of the Mississippian Barnett shale. J. Sediment. Res. 2009, 79(12): 848-861.

Lyu, Q., Ranjith, P.G., Long, X., et al. A review of shale swelling by water adsorption. J. Nat. Gas Sci. Eng. 2015, 27(11): 1421-1431.

Makhanov, K., Habibi, A., Dehghanpour, H., et al. Liquid uptake of gas shales: A workflow to estimate water loss during shut-in periods after fracturing operations. J. Unconv. Oil Gas Resour. 2014, 7: 22-32.

Mastalerz, M., Hampton, L., Drobniak, A., et al. Significance of analytical particle size in low-pressure $\mathrm{N}_{2}$ and $\mathrm{CO}_{2}$ adsorption of coal and shale. Int. J. Coal Geol. 2017, 178: 122-131.

Mccutcheon, A.L., Barton, W.A., Wilson, M.A. Characterization of water adsorbed on bituminous coals. Energy Fuels 2003, 17(1): 107-112.

Mooney, R.W., Keenan, A.G., Wood, L.A. Adsorption of water vapor by montmorillonite. I. Heat of desorption and application of BET theory. J. Am. Chem. Soc. 1952, 74(6): 1367-1371.

Nicot, J.P., Scanlon, B.R. Water use for shale-gas production in Texas, U.S. Environ. Sci. Technol. 2012, 46(6): 35803586.

Puri, B.R., Murari, K., Singh, D. The sorption of water vapor by charcoal as influenced by surface oxygen complexes. J. Phys. Chem. 1961, 65(1): 37-39.

Ross, D.J.K., Bustin, R.M. The importance of shale composition and pore structure upon gas storage potential of shale gas reservoirs. Mar. Pet. Geol. 2009, 26(6): 916-927.

Sander, M., Lu, Y., Pignatello, J.J. A thermodynamically based method to quantify true sorption hysteresis. J. Environ. Qual. 2005, 34(3): 1063-1072.

Sang, G., Liu, S., Elsworth, D. Water vapor sorption properties of Illinois shales under dynamic water vapor conditions:
Experimentation and modeling. Water Resour. Res. 2019, 55(8): 7212-7228.

Serbezov, A. Adsorption equilibrium of water vapor on F-200 activated alumina. J. Chem. Eng. Data 2003, 48(2): 421425.

Shen, W., Li, X., Cihan, A., et al. Experimental and numerical simulation of water adsorption and diffusion in shale gas reservoir rocks. Adv. Geo-Energy Res. 2019, 3(2): 165174.

Shen, W., Li, X., Lu, X., et al. Experimental study and isotherm models of water vapor adsorption in shale rocks. J. Nat. Gas Sci. Eng. 2018, 52(4): 484-491.

Singh, H. A critical review of water uptake by shales. J. Nat. Gas Sci. Eng. 2016, 34(8): 751-766.

Sing, K.S. Reporting physisorption data for gas/solid systems with special reference to the determination of surface area and porosity (Recommendations 1984). Pure Appl. Chem. 1985, 57(4): 603-619.

Švábová, M., Weishauptová, Z., Přibyl, O. Water vapour adsorption on coal. Fuel 2011, 90(5): 1892-1899.

Tang, X., Ripepi, N., Valentine, K.A., et al. Water vapor sorption on Marcellus shale: Measurement, modeling and thermodynamic analysis. Fuel 2017, 209(12): 606614.

Thommes, M., Kaneko, K., Neimark, A.V., et al. Physisorption of gases, with special reference to the evaluation of surface area and pore size distribution (IUPAC Technical Report). Pure Appl. Chem. 2015, 87(9-10): 1051-1069.

Timmermann, E.O. Multilayer sorption parameters: BET or GAB values? Colloid. Surf. A-Physicochem. Eng. Asp. 2003, 220(1): 235-260.

Tinni, A., Sondergeld, C., Rai, C. Particle size effect on porosity and specific surface area measurements of shales. Paper SCA 2014-013 Presented at International Symposium of the Society of Core Analysts, Avignon, France, 8-11 September, 2014.

Vandecasteele, I., Marí, R.I., Sala, S., et al. Impact of shale gas development on water resources: A case study in northern Poland. Environ. Manage. 2015, 55(6): 12851299.

Wang, L., Zhang, G., Hallais, S., et al. Swelling of shales: A multiscale experimental investigation. Energy Fuels 2017, 31(10): 10442-10451.

Yamashita, K., Endo, A., Daiguji, H. Water adsorptiondesorption behavior of two-dimensional hexagonal mesoporous silica around freezing point. J. Phys. Chem. C 2013, 117(5): 2096-2105.

Yang, R., Hao, F., He, S., et al. Experimental investigations on the geometry and connectivity of pore space in organicrich Wufeng and Longmaxi shales. Mar. Pet. Geol. 2017, 84(6): 225-242.

Yang, R., He, S., Hu, Q., et al. Comparative investigations on wettability of typical marine, continental, and transitional shales in the middle Yangtze Platform (China). Energy Fuels 2018a, 32(12): 12187-12197.

Yang, R., He, S., Yi, J., et al. Nano-scale pore structure and fractal dimension of organic-rich Wufeng-Longmaxi shale from Jiaoshiba area, Sichuan Basin: Investigations 
using FE-SEM, gas adsorption and helium pycnometry. Mar. Pet. Geol. 2016, 70(2): 27-45.

Yang, R., Hu, Q., He, S., et al. Pore structure, wettability and tracer migration in four leading shale formations in the Middle Yangtze Platform, China. Mar. Pet. Geol. 2018b, 89: 415-427.

Yang, R., Hu, Q., Yi, J., et al. The effects of mineral composition, TOC content and pore structure on spontaneous imbibition in Lower Jurassic Dongyuemiao shale reservoirs. Mar. Pet. Geol. 2019, 109: 268-278.

Yang, R., Jia, A., He, S., et al. Water adsorption characteristics of organic-rich Wufeng and Longmaxi Shales, Sichuan Basin (China). J. Pet. Sci. Eng. 2020, 193: 107387.

Zhang, J., He, S., Yan, X., et al. Structural characteristics and thermal evolution of nanoporosity in shales. Journal of China University of Petroleum 2017, 41(1): 11-24. (in Chinese)
Zhang, R., Liu, S. Experimental and theoretical characterization of methane and $\mathrm{CO}_{2}$ sorption hysteresis in coals based on Langmuir desorption. Int. J. Coal Geol. 2017, 171: 49-60.

Zhou, S., Ning, Y., Wang, H., et al. Investigation of methane adsorption mechanism on Longmaxi shale by combining the micropore filling and monolayer coverage theories. Adv. Geo-Energy Res. 2018, 2(3): 269-281.

Zolfaghari, A., Dehghanpour, H., Holyk, J. Water sorption behaviour of gas shales: I. Role of clays. Int. J. Coal Geol. 2017a, 179(6): 130-138.

Zolfaghari, A., Dehghanpour, H., Xu, M. Water sorption behaviour of gas shales: II. Pore size distribution. Int. J. Coal Geol. 2017b, 179(6): 187-195.

Zou, J., Rezaee, R., Xie, Q., et al. Investigation of moisture effect on methane adsorption capacity of shale samples. Fuel 2018, 232: 323-332. 